\title{
CERVICAL FRACTURE WITH PIRIFORM SINUS LACERATION
}

\author{
MIHAELA CHIALDA ${ }^{1}$ \\ ${ }^{I}$ Sibiu County Clinical Emergency Hospital
}

\begin{abstract}
Keywords: $\quad$ fracture, Abstract: Particular case of complex cervical trauma by associating a cervical fracture with piriform laceration, piriform sinus sinus laceration. The trauma is located in the anatomo-topographic zone II. Delayed onset at 24 hours of digestive symptoms, swallowing disorders, sialorrhea, dysphagia, subcutaneous cervical emphysema. CT with Optiray contrast agent is performed, an investigation that reveals a gap in the left piriform sinus of 5-6 mm. The evolution is favourable under conservative treatment, nasogastric tube, broad spectrum antibiotic treatment.
\end{abstract}

\section{INTRODUCTION}

As the incidence of violent trauma is increasing nowadays, the rate of trauma to the neck and head is also increasing. At present, penetrating neck injury comprises $5 \%$ to $10 \%$ of all trauma cases.

All penetrating neck wounds are potentially dangerous and require emergency treatment. In the neck region there are many sensitive and vital structures, all merged in a small area that is not protected by bone tissue. $(1,2)$ These can be divided into 4 groups: airways (trachea, larynx, fringe and lungs), blood vessels (carotid, jugular, subclavian artery, aortic arch), gastrointestinal tract (pharynx and esophagus) and nerve structures (brachial pleura, peripheral nerves, spinal cord, cranial nerves).

The signs and symptoms specific to the structures in all 4 groups should alert the otolaryngologist that trauma has occurred at this level. The neck can be divided into 3 anatomotopographic areas. $(1,3,4)$

Zone $\mathrm{I}$ is located under the cricoid cartilage, being an area where important vacuole structures are protected by the rib cage and collarbones.

Zone II is the area above the cricoid cartilage to the level of the mandible. Zone II does not have bone protection, thus being more exposed to trauma with a rate of $65-70 \%$.

The least common traumas in zone II are venous and pharyngoesophageal because they are not diagnosed in the initial assessments.

A substantial number of patients can be selectively managed, depending on sings, symptoms and direction of the trajectory. When patients are stable and lack physical signs of obvious major neck injury, they are evaluated by diagnostic radiologic and endoscopic techniques. All patients are admitted for observation, in the next $24 \mathrm{~h}$ after trauma, clinical and physical examinations being repeated. $(1,2,3)$

\section{CASE REPORT}

A 63-year-old patient presented to the Emergency Room within the Sibiu County Clinical Emergency Hospital, presenting the following symptoms: pain in the cervical region, headache, dizziness that started suddenly following a spinal trauma by falling objects in the cervical region.

At the general emergency consultation, the patient presents: relatively good general condition, preserved state of consciousness, cervical area immobilized in Minerva type collar, hyperstenic constitution, respiratory rate 19 , afebrile, heart rate 103, tachycardia, rhythmic noises, well beaten, blood pressure within normal limits, clean, normally coloured skin with contusion present at the cervical level. Integral and mobile osteoarticular system, no eye disorders, no open trauma. The patient is admitted to the neurosurgery department for specialized treatment.

Neurological examination at hospitalization: conscious patient, temporo-spatially oriented, Glasgow Coma Scale 15 points, no meningeal signs or pathological reflexes, reflexivity and motility preserved, no sphincter disorders, cortical functions preserved.

At 24 hours after admission, the patient complains of dysphagia with inability to swallow fluids, solids, sialorrhea, sore throat, voice change, crackling in the neck, subcutaneous emphysema, subfebrile.

After examination by a general surgery specialist, a traumatic esophageal injury is suspected. CT is performed with the ingestion of the Optiray contrast substance, which reveals the rupture of the piriform sinus, blood collection at this level and retropharyngeal, aerial collection in the soft parts, cervical prevertebral and upper mediastinum. Upper digestive endoscopy reveals left hypopharyngeal hematoma and an ulceration of approximately $5-6 \mathrm{~mm}$. Thus, the immobilized patient with a soft cervical collar is transferred to the Otorhinolaryngology department, where the nasogastric tube is urgently mounted and antibiotic therapy is initiated with Cefuroxim, Metronidazole, Fluconazole for 10 days. Following the treatment performed, the evolution is favourable.

A CT scan is performed that reveals a cervical region within normal limits. C1-C6 cervical spine radiograph (AP, LL) in conjunction with previous $\mathrm{CT}$ examinations, reveals:

Small bone fragment projected antero-inferiorly by the spinous process $\mathrm{C} 5$ of about $1 \mathrm{~cm}$, parcel fracture with

${ }^{1}$ Corresponding author: Mihaela Chialda, B-dul. C. Coposu, Nr. 2-4, Sibiu, România, E-mail: mihaela_chialda@yahoo.com, Phone: +40744 551390 Article received on 20.09.2020 and accepted for publication on 08.01.2021 


\section{CLINICAL ASPECTS}

displacement. It does not show spondylolisthesis or vertebral body subsidence. Spondylarthrosis degenerative changes with anterior osteophytosis.

Narrowing of the distal space and reversal of the physiological curve at C5-C6. No pathological changes in the soft prevertebral parts.

\section{Figure no. 1. Cervical native CT scan}

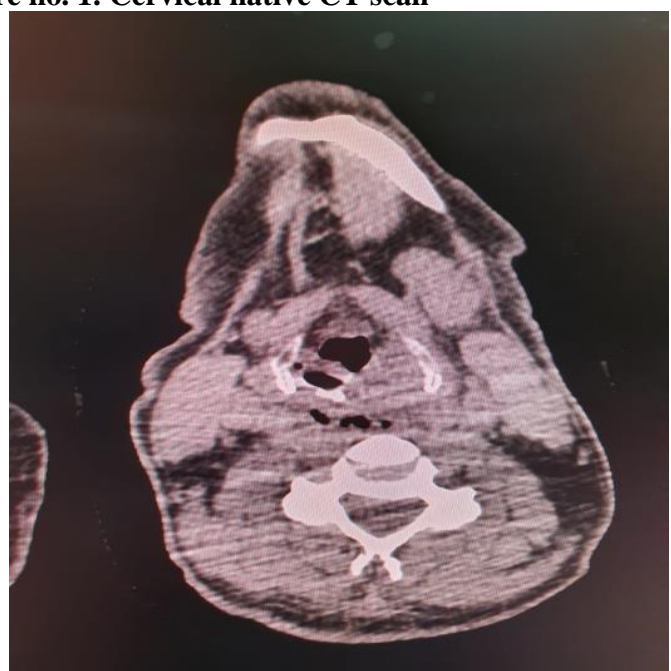

Figure no. 2. Cervical native CT scan

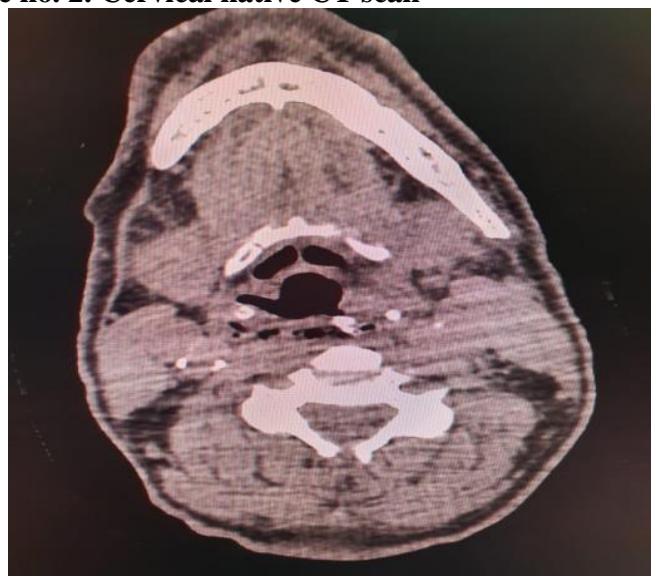

\section{DISCUSSIONS}

We presented a case of complex cervical trauma, with fracture of spinous processes $\mathrm{c} 5-\mathrm{c} 6$, fracture by compaction of vertebral body c7 with small bone fragment projected anteroinferiorly by spinous apophysis c5, a parcel fracture with displacement, which secondarily affects the sinus piriform. It should be noted that the gap in the piriform sinus was 5-6 mm, a fact highlighted by endoscopy.(4) This trauma is located in topographic area 2 , and the vital signs were good, the patient being hemodynamically stable, without hypovolemic shock or hemomediastinum.

This justified us for a conservative treatment, without performing an exploratory cervicotomy. $(1,3,5,6,7,8)$ The case was initially labelled as a neurosurgical case by symptomatology and paraclinical examination in the emergency department.(1) At 24 hours after hospitalization, the patient presents with subcutaneous cervical emphysema and swallowing disorders, which raises the suspicion of damage to the digestive tract, which is why cervical CT is repeated with Optiray contrast ingestion and endoscopy, which reveals the piriform sinus lesion. $(9,10)$
In the assessment of pharyngo-esophageal trauma, radiological examination with the ingestion of the contrast substance Gaastrografin or Optiray is necessary to highlight the lesions, because the administration of barium can radiographically distort the soft tissues and is even more toxic. If at the radiological evaluation, no changes are observed, but we still suspect a pharyngo-esophageal lesion, barium can also be administered. Pharyngeal-esophageal endoscopic evaluation is important in cervical trauma.(1)

In cervical spine fractures, rigid esophagoscopy should be avoided. Omission of cracks or tears in the cricopharyngeal and hypopharyngeal can lead to serious complications such as mediastinitis, increasing morbidity and mortality considerably.

Thus, if there is the slightest suspicion of perforation at this pharyngeal level, it is very important to suppress food by mounting a nasogastric tube and initiating broad-spectrum antibiotic therapy, to avoid major complications.(1)

\section{CONCLUSIONS}

Cervical injuries are constantly increasing and can affect several anatomical elements in the region, which involves a complex examination of the case and proper monitoring.

Severe life-threatening cases due to massive hemorrhage, expansive hematoma, hemodynamic instability, hemomediastinum or hypovolemic shock require exploratory cervicotomy with ligation or suturing of large vessels, tracheostomy, pharyngorrhagia.

For stable patients with cervical trauma in topographic area 2 , the evolution of symptoms is monitored and massive broad-spectrum antibiotic therapy is administered, covering gram-positive and gram-negative aerobic and anaerobic germs.

Complex cases of cervical trauma require a cooperative, multidisciplinary approach, thus, in any traumatology team, the otorhinolaryngologist must be included, in order to evaluate and treat the pharyngolaryngeal and vascular traumas.

\section{REFERENCES}

1. Cummings CW, Haughey BH, Thomas JR, Lee A. Harker LA, Flint PW. Otolaryngology Head\&Neck Surgery Cumings, Ed. Elsevier Mosby Fourth Edition. 2004;3:2525-2538

2. Anniko M, Bernal-Sprekelsen M, Bonkowsky MV, Bradley P, Iurato S. Otorhinolaryngology Head\& Neck Surgery, Ed. Springer; 2010. p. 503-505.

3. Anghelina F, Beuran M, Borangiu A, Popescu I, Constantin Ciuce C, Sarafoleanu C. Otorinolaringologie Si Chirurgie Cervico-Faciala Sub Redactia Irinel Popescu, Ed. Academiei Romane; 2012. p. 691-695.

4. Greenberg MS. Hand Book Of Neurosurgery, Ed.Thieme, Eighth Edition - Traumatisme Cervicale; 2019.

5. Anghel I. Otorinolaringologia Ed. Universitara Carol Davila; 2013. p. 190-193.

6. Popescu CR, Zainea V. Otorinolaringologie, Ed. Universitara Carol Davila; 2010. p. 256-257.

7. Zenner HP. Otorinolaringology, Ed. Mirton; 2004. p. 284285.

8. Goldenberg D, Golstein B I. Neck Trauma Hand Book of Otolaryngologye, Ed. Thieme; 2011.

9. Becker W, Naumann HH, Pfaltz CR. Ear, Nose, Throat Disease, Ed. Thieme; 1994. p. 409-413.

10. Sarafoleanu D. Explorarea Paraclinica Si Functionala In Otorinolaringologie Vol. II Ed. Albatros, Explorare Laringe; 2000. 